\title{
Finalidade pública, autoridade governamental e poder coletivo
}

Jocelyne Bourgon

Texto da Conferência XIV Congresso Internacional do CLAD Salvador, Babia, Brasil 27-30 Outubro, 2009

\section{Introdução}

Os processos de reforma de Estado e do setor público variam em diferentes países e regiões. Eles refletem diferentes circunstâncias, necessidades e filosofias sobre o papel do governo na sociedade.

Desde a década de 1980, as reformas têm dominado as agendas governamentais em todo o mundo. Algumas estiveram focadas em restaurar a saúde fiscal do governo e reequilibrar o papel do governo na sociedade. Muitas têm tentado aproveitar os benefícios da globalização e atenuar seus impactos negativos. A maioria das reformas do setor público se concentra em aprimorar o desempenho, a eficiência e a responsabilização, melhorando a prestação de serviços, aumentando a satisfação do usuário e adotando várias abordagens de governo eletrônico para alavancar o poder das tecnologias de informação e comunicação. 
O contexto no qual essas reformas foram moldadas tem sido igualmente extraordinário. Este período testemunhou a queda do Muro de Berlim; o nascimento e a expansão da União Europeia; a integração das economias regionais; e o surgimento de novos blocos regionais ancorados em torno da China, Índia e Brasil. A estrutura de poder bipolar que caracterizou o mundo durante a Guerra Fria foi transformada em uma geometria de relações de poder complexa e em constante mudança. Em resposta, os governos estão buscando arranjos de governança nacionais, regionais, internacionais e globais melhores.

Durante a maior parte deste tempo, tem havido também um período prolongado de crescimento. Com certeza, o crescimento e os benefícios daí resultantes têm sido desiguais. Houve contratempos, gargalos e crises.

"Que você viva em tempos interessantes" alguém disse uma vez. E com certeza isso tem acontecido. $\mathrm{O}$ contexto das reformas do setor público está sempre mudando.

Refletindo sobre as últimas três décadas, podemos ver que os governos ao redor do mundo embarcaram em uma jornada notável de experimentação e inovação. A natureza e o ritmo das reformas têm sido extraordinários.

O ritmo das reformas provavelmente não se reduzirá, porque as organizações do setor público ainda não estão alinhadas com o novo contexto global e com os complexos problemas que têm como missão resolver.

Muitas instituições públicas nasceram no final do século XIX ou início do século XX, um período caracterizado pela revolução industrial, a emergência das burocracias públicas nas sociedades democráticas e a influência da administração científica. Esperava-se que as organizações do setor público executassem tarefas previsíveis a partir de regras prescritas. A estrutura de poder era de cima para baixo, hierarquizada. Controles rigorosos asseguravam desempenho e responsabilização para a autoridade que era delegada. Ao longo do tempo, algumas dessas características e práticas originais mudaram em resposta a realidades em mudança. Entretanto, em geral, o modelo da era industrial ainda é o cerne de muitas organizações públicas.

Embora esse modelo tenha servido bem a governos e sociedades, ele já não é suficiente (Baltodano, 1997; Khator, 1994). Um número crescente de desafios na política pública exige a participação ativa de muitos atores de dentro e fora do governo, incluindo o setor privado, a sociedade civil, os cidadãos e as comunidades. Isso exige que o governo trabalhe para além das fronteiras convencionais, utilizando redes, processos de participação pública e outros meios (HuddLesTon, 2000; InNES e Booher, 2004; KLIJN, 2005), e força o governo a utilizar sua autoridade e recursos para habilitar e empoderar outros. $\mathrm{O}$ aumento da complexidade e da incerteza nos contextos das políticas e de governança está levando os governos a melhorar a sua capacidade de antecipar, intervir, inovar, aprender, ser ágil e recuperar-se de choques e crises. Há uma crescente necessidade de flexibilidade e compartilhamento de informação e conhecimento, contra os quais militam os modelos organizacionais e de governança tradicionais.

Futuras reformas do setor público precisarão continuar empurrando o governo para além do seu papel tradicional de tomador de decisões em nome dos cidadãos e de prestador de serviços para os cidadãos. Elas irão explorar o 
modo como os governos podem trabalhar com os cidadãos e outros atores para produzir resultados de valor público elevado.

Essas reformas exigirão:

a) uma definição mais ampla de resultados públicos que enfatize a importância das políticas públicas e dos resultados cívicos;

b) uma visão ampliada dos papéis do governo e dos cidadãos, que promova o uso da autoridade do governo para liberar o poder coletivo dos cidadãos e da sociedade de forma a obter resultados de alto valor público;

c) uma compreensão mais dinâmica de governança e da administração pública que dê suporte à construção das capacidades necessárias para se buscar os interesses coletivos e o bem público, em um ambiente global cada vez mais imprevisível.

Este artigo explora em que podem se constituir essas três trajetórias de reforma e propõe algumas iniciativas para ajudar servidores públicos face aos desafios e dilemas de servir no século XXI.

\section{Em busca de políticas públicas e resultados cívicos}

O papel das organizações públicas é alcançar resultados de elevado valor público de forma a evoluir princípios cívicos - ou o que muitos estados reconhecem como princípios democráticos (VAN DOOREN, Thijs e Bouckaert, 2004). Desempenho elevado no setor público inclui a execução de políticas públicas e a obtenção de resultados cívicos (ver Figura 1).

\section{Resultados de políticas públicas}

No governo, nenhuma unidade organizacional, agência ou departamento trabalha sozinho; nenhuma atividade, serviço ou programa é autossuficiente. $\mathrm{Na}$ maioria de suas políticas, os governos

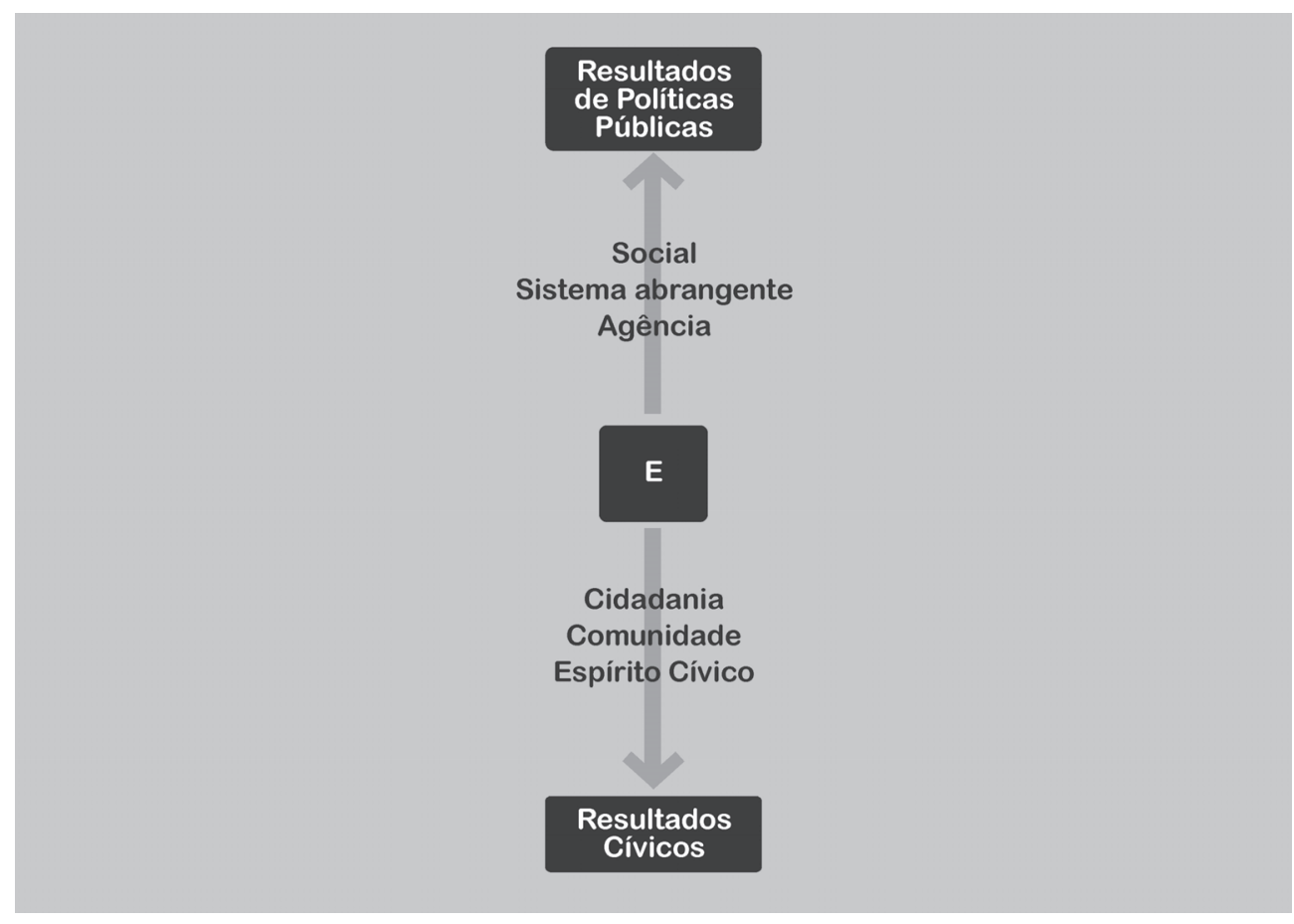

Figura 1: Alcançando políticas públicas e resultados cívicos 
alcançam resultados por intermédio de uma combinação de instrumentos, tais como leis, regulamentos, créditos fiscais e transferências de renda para indivíduos ou de fundos para outros níveis de governo (Salamon, 2002). Alcançar resultados de elevado valor público no governo muitas vezes é um esforço coletivo que atravessa as fronteiras de programas ou agências. Além disso, os governos obtêm resultados por intermédio de trabalho com imensas redes de atores e organizações, incluindo cidadãos e grupos da sociedade civil, que têm interesse em obter resultados comuns com a política.

Resultados de programas e de agências individuais são importantes, uma vez que ligam insumos - como o dinheiro dos contribuintes - aos produtos e à satisfação do usuário. Entretanto, os resultados que são mais relevantes para os cidadãos e gestores eleitos normalmente ultrapassam o âmbito dos programas em si, dos diferentes serviços e das organizações individuais. A verdadeira medida do programa governamental de sucesso é a sua contribuição para os resultados sociais e do sistema como um todo (Bourgon, 2008a). Por exemplo, uma grande satisfação do usuário com um determinado serviço médico não é necessariamente sinal de sucesso, se esses resultados são obtidos utilizando recursos escassos que poderiam ser empregados em outras ações estratégicas na área da saúde. Da mesma forma, os sucessos de um departamento obtidos à custa de resultados mais amplos de governo não demonstram desempenho ou qualidade.

As organizações do setor público têm a responsabilidade de explorar as possibilidades de como mover suas contribuições para pontos mais elevados na cadeia de valor agregado dos resultados. Elas precisam integrar seus esforços para alcançar os objetivos sistêmicos e da sociedade e medir o valor de suas contribuições relativas para os resultados de sistema e de sociedade. Os governos de diferentes partes do mundo começaram a prestar mais atenção aos resultados de sistema. Poucos têm focado em resultados sociais. ${ }^{1}$

$O$ foco no sistema e na sociedade oferece mais perspectiva do que a ênfase que tem sido colocada, desde o início dos anos 1990, na mensuração e na gestão de desempenho no nível micro (BOURGon, 2008b). É de especial importância que os resultados cívicos e das políticas públicas sejam convergentes de maneira mais significativa para obter resultados sociais. Esses são resultados da coletividade obtidos por todos os agentes, tanto da esfera pública ou privada quanto da sociedade civil. Eles refletem o estado da sociedade para os cidadãos e para os tomadores de decisão, contribuindo para moldar os interesses coletivos que, por sua vez, subsidiam as ações do governo e dos cidadãos. Cada vez mais pessoas desejam contribuir na identificação e definição de interesses coletivos; os cidadãos não estão satisfeitos em apenas votar a cada quatro ou cinco anos.

\section{Resultados cívicos}

Espera-se que as organizações do setor público satisfaçam o ideal dos princípios democráticos e fomentem os resultados cívicos, o que elas podem fazer de várias maneiras. Podem permitir a fiscalização pela Assembleia Legislativa; garantir que os titulares de cargos públicos sejam responsabilizados pelo exercício do poder; prover a transparência; garantir o acesso dos cidadãos à informação; incentivar a participação do cidadão no ciclo de política pública para garantir uma representação de interesses mais ampla e equitativa; e maior 
comprometimento e apoio às iniciativas do governo (BOURGON, 2009).

Esses princípios e medidas constituem o que a Organização para a Cooperação Econômica e Desenvolvimento (OCDE, 2008) chama de "governo aberto e inclusivo", em direção ao qual muitos países, incluindo nações latino-americanas, fizeram progressos nos últimos anos. Vários governos adotaram legislação de acesso à informação. ${ }^{2}$ Muitos governos têm aproveitado tecnologias de comunicação para melhorar e promover maior acesso a seus serviços. ${ }^{3}$ Alguns estão usando pesquisas de satisfação regularmente e outros para processos de avaliação e feedback. Há também países que criaram "a janela-única”, centros de serviços integrados para incentivar a coordenação interdepartamental e garantir que os cidadãos não fiquem presos nos "labirintos da burocracia". Outros descentralizaram a prestação de serviços para o nível local de forma a garantir melhor acesso e que os serviços satisfaçam as necessidades específicas das diversas comunidades. ${ }^{4}$ Outros países têm usado canais, como os painéis de cidadãos e orçamento participativo, para incentivar a participação deliberativa e outras formas de engajamento do cidadão. ${ }^{5}$

No entanto, ainda mais pode ser feito. Resultados cívicos incluem, mas não se limitam a, uma cidadania ativa, comunidades empoderadas, e um espírito ć́vico que permeia a sociedade e incentiva a ação coletiva para o bem comum. É possível melhorar os resultados cívicos da maioria dos programas e atividades de governo tomando-se medidas para remover as barreiras que impedem a cidadania ativa e incentivando a construção de capacidades comunitárias e coletivas.

Nas últimas duas décadas, os governos têm colocado muita ênfase - talvez demasiada - sobre os desafios da participação dos cidadãos em novas iniciativas de políticas públicas (por exemplo, OCDE, 2008; NAÇões Unidas, 2007). Durante qualquer mandato, o governo pode lançar um conjunto de novas iniciativas de políticas, ao mesmo tempo em que executa milhares de políticas, programas e serviços existentes. As atividades existentes surgiram da vontade política, das decisões políticas e das escolhas de políticas feitas por

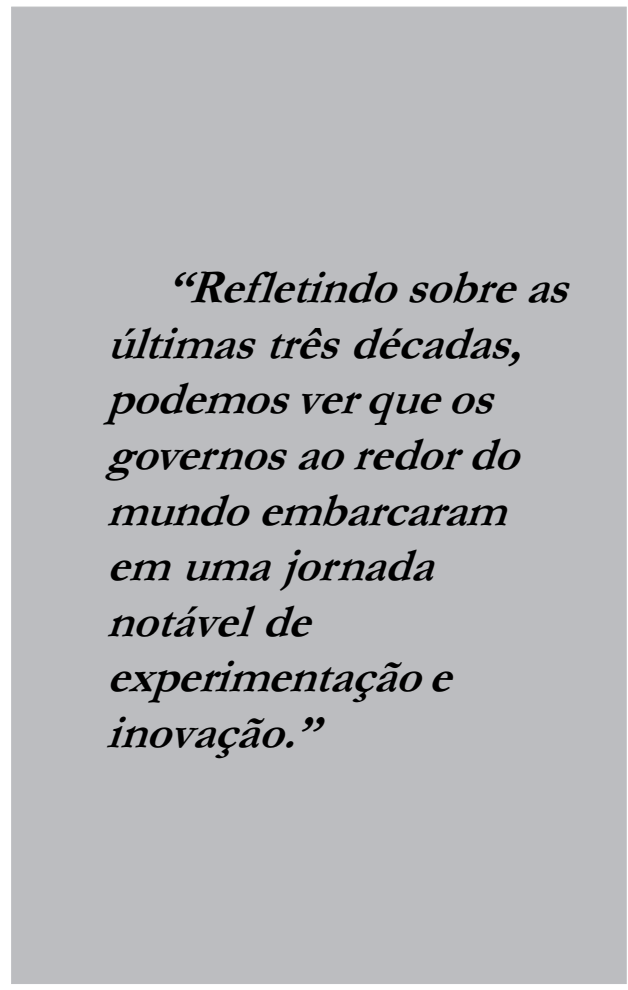

sucessivos governos para expressar os interesses coletivos dos cidadãos. Muitas dessas atividades, se não todas, poderiam se beneficiar de algum tipo de envolvimento dos cidadãos, que poderiam melhorar seu desempenho democrático e, com ele, a qualidade dos resultados públicos.

Um compromisso explícito de melhorar os resultados cívicos implicaria explorar um papel mais expressivo para os cidadãos e 
suas comunidades ao longo de uma série de vetores.

- Transparência e responsabilização (accountability): Expandir o conceito de responsabilização de um processo de prestação de contas para o exercício de poder por parte dos gestores públicos, ampliálo para a responsabilização pública visando resultados sociais e sistêmicos. Isso pode assumir a forma de um sistema abrangente de informação/notificação pública, como um cartão de controle, ou uma abordagem mais ambiciosa, como um sistema de responsabilização compartilhada no qual vários atores estão envolvidos.

- Acesso: Progredir com o governo eletrônico, permitindo o acesso dos cidadãos ao governo (incluindo conhecimentos detidos pelo governo) em seus termos e de acordo com suas necessidades. Isso contribuiria para o desenvolvimento de uma infraestrutura de conhecimento moderno para facilitar a criação de redes, incentivar a inovação coletiva e permitir que governos e cidadãos formatem e mantenham a inteligência coletiva da nossa sociedade em rede.

- Voz: Expansão das avenidas para integrar as vozes dos cidadãos e suas comunidades nos aspectos relevantes da administração pública. Isso inclui explorar o potencial para integrar mecanismos de retroalimentação para melhoria do ciclo do programa, a construção de plataformas de comunicação que permitam aos cidadãos ouvir as vozes uns dos outros, assim como interagir uns com os outros e com os prestadores de serviços para melhorar os resultados. Também implicaria remover barreiras no sentido de ouvir as vozes das pessoas mais vulneráveis, os menos alfabetizados, os pobres, os jovens e os idosos.

- Escolha: Em vez de ter funcionários públicos exercendo todos os poderes discricionários que decorrem da flexibilidade que existe na maioria dos programas e atividades do governo, permitir que os cidadãos e as comunidades exerçam a discricionaridade em seu próprio nome para satisfazer suas próprias necessidades, dentro da lei, e respeitando as responsabilizações profissionais e políticas.

- Ação: Incentivar o papel ativo dos cidadãos e das comunidades como criadores de valores e como agentes ativos na produção de bens públicos, criando soluções para problemas comuns e delineando o futuro que desejam.

É importante notar que o vasto conjunto de iniciativas apoiadas pelo "governo mais aberto e inclusivo" tem gerado algumas preocupações e confusão (Bourgon, 2009). Entre elas a preocupação de que a consulta e a participação cidadã podem custar caro, atrasar decisões e impedir a tempestividade das ações (IRVIN e Stansbury, 2004); a participação tornase um dogma de tal forma que maior participação do cidadão é sempre considerada como melhor (é o único melhor caminho de se fazer as coisas no governo), e que os processos de consulta podem ser capturados por grupos de interesse. Além disso, existe uma confusão entre os servidores públicos quanto ao que os políticos e os cidadãos esperam deles.

A participação do cidadão e da comunidade não é um substituto para a democracia representativa e a vontade política. Ela só pode se dar no âmbito das leis e da constituição em vigor, e de uma forma que respeite as instituições públicas legítimas e a autoridade do governo. O governo tem a autoridade e é responsável pela definição da agenda e das regras de engajamento. ${ }^{6}$

A participação do cidadão e da comunidade não é uma panaceia e não é 
apropriada em todos os casos. O governo precisa usá-la de forma deliberada e sábia. A participação dos cidadãos tem valor intrínseco e instrumental. Tem valor intrínseco na medida em que incentiva uma cidadania ativa, o empoderamento das comunidades e o espírito cívico. Tem valor instrumental na medida em que pode ajudar a aumentar o apoio às iniciativas do governo e melhores resultados das políticas públicas. ${ }^{7}$ Considerando que uma era anterior criou para alguns países o ditado "não há tributação sem representação", uma máxima mais contemporânea deveria ser "não há ação cívica sem participação." No mínimo, os governos precisam envolver cidadãos e outros atores, quando esperam que eles desempenhem um papel ativo como "agentes" de políticas públicas. Há um número crescente de questões políticas complexas que requerem que cidadãos e outros atores desempenhem papéis ativos, desde a redução das emissões de carbono, das taxas de obesidade ou do racismo, até o aumento das taxas de alfabetização ou a melhoria da segurança pública. Tais desafios requerem a participação dos cidadãos e suas comunidades, bem como a contribuição de diferentes partes interessadas. Sem a participação, as iniciativas de governo enfraquecerão. Quando mal concebidos, os esforços de engajamento do cidadão podem se tornar uma empreitada exclusiva ao invés de inclusiva, onde dominam as vozes poderosas de alguns "poucos escolhidos".

A primeira responsabilidade do governo é criar ambiente favorável que remova as barreiras à participação dos grupos geralmente excluídos, incluindo: os jovens que não podem votar, mas são muitas vezes confrontados com a dívida decorrente da prestação de serviços para as gerações no poder; os pobres, cujas vozes devem ser ouvidas para a obtenção da equidade e justiça social; as mulheres que, na maioria dos países, ainda estão subrepresentadas em papéis de tomada de decisão formal e que enfrentam barreiras físicas e sociais para sua participação; e os afetados por barreiras especiais devido a idade, deficiência, distância geográfica e analfabetismo.

A segunda responsabilidade do governo é a construção de canais que permitam às pessoas decidir por si próprias se querem participar e quando fazê-lo. Com certeza ninguém quer participar de todas as questões, mas devem-se disponibilizar canais de participação que sejam de fácil acesso e utilização para todos.

A participação cidadã consome tempo e recursos, embora o aumento da utilização de tecnologias de informação e comunicação nesta área possa reduzir custos (Irvin e StANSBURY, 2004). No entanto, talvez estes não sejam os custos mais significativos a considerar. Desde a década de 1960, tem-se observado uma queda da confiança no governo e nas instituições do setor público em todo o mundo (NyE, ZeLIKOV e KING, 1997; Pharr e Putnam, 2000). A redução da confiança é um custo para o governo e a sociedade como um todo. Nenhum país é rico o suficiente para pagar o preço da desconfiança. Ela pode levar a uma variedade de resultados negativos para governo e sociedade, incluindo a redução do escopo para abordagens de política pública, baixo grau de conformidade voluntária, evasão fiscal, corrupção, agitação social, instabilidade e até violência. Embora ainda seja muito cedo para avaliar se o fortalecimento e aprofundamento da participação dos cidadãos e da comunidade reverterão essa tendência, certamente vale o preço e o esforço.

O desafio para o governo é alcançar resultados de políticas públicas e cívicos - 
não um ou outro, e não um em detrimento do outro. Os resultados cívicos aumentam a credibilidade dos governos, os de políticas públicas aumentam a legitimidade do governo. Combinadas, credibilidade e legitimidade reforçam a confiança dos cidadãos no governo, instituições públicas e organizações do setor público.

Otimizar os resultados das políticas públicas e os resultados cívicos é um difícil ato de equilíbrio. Exige julgamento refinado e só pode ter sucesso na prática se levar em conta contexto, cultura e circunstâncias. Em particular, os administradores públicos devem mediar entre ganhos de eficiência e a necessidade de envolver cidadãos e comunidades, mesmo à custa de algum grau de eficiência. A melhoria dos resultados cívicos aumenta a capacidade coletiva da sociedade de alcançar melhores resultados públicos ao longo do tempo, mesmo que envolva um custo maior no curto prazo. Um foco em resultados cívicos posiciona cidadãos e suas comunidades como agentes ativos na formação dos interesses coletivos e como criadores de valor na produção de resultados públicos.

Muitos países têm feito grandes progressos no sentido de alcançar melhores resultados no setor público. No entanto, em geral, administradores públicos têm trabalhado a partir de uma definição incompleta de resultados públicos - definição essa que não confere peso suficiente aos resultados cívicos. Eles também têm permitido alto grau de separação entre os resultados das políticas públicas e os resultados cívicos na avaliação da contribuição das organizações públicas para a sociedade.

O desafio da incorporação de um foco em resultados ć́vicos em todas as atividades do governo em pé de igualdade com a busca de resultados de políticas públicas não se limita apenas às sociedades com formas convencionais e formais de governança democrática. Aplica-se a países com ou sem eleições e com ou sem mais de um partido (Mahbubani, 2009). Em todo o mundo, os cidadãos procuram desempenhar um papel mais ativo nas áreas de maior importância para eles (FUNG e Wright, 2003). Governos ignoram as vozes de seus povos à sua conta e risco.

\section{Autoridade do governo e o poder coletivo: os papéis do governo e dos cidadãos}

Tradicionalmente, o governo é visto como o principal agente na definição do bem público e no serviço ao interesse coletivo. Segundo essa visão, o governo define a agenda para a mudança, propõe novas leis e implementa as já existentes. O governo é o provedor de serviços públicos, o legislador e o mediador que arbitra entre interesses conflitantes. Nessa perspectiva convencional, os cidadãos são vistos como sujeitos de direito, contribuintes e beneficiários de programas do governo. Mais recentemente, passaram a ser vistos como usuários de serviços públicos e clientes das organizações públicas. Como resultado, muitas reformas do setor público têm-se centrado na prestação direta de serviços para os cidadãos.

Esse ponto de vista sobre os papéis do governo em relação aos cidadãos e suas manifestações nas agendas de reforma talvez tenha sido demasiado estreito para assegurar resultados de alto valor público, particularmente com relação às questões cada vez mais complexas enfrentadas por governos e cidadãos em um mundo globalizado e imprevisível. Vários desdobramentos já deixam isso claro:

- A importância da prestação direta de serviços está em declínio. Ferramentas indiretas, tais como transferências 
para indivíduos e outras esferas de governo, créditos fiscais, vouchers, subvenções, empréstimos e prestação de serviços indiretos através de terceiros ou parcerias público-privadas representam a maior parte da atividade e da despesa do governo. Essas ferramentas têm reduzido o papel direto do governo na produção de bens e serviços públicos (SaLAmon, 2002).

- Os governos não atuam sozinhos. Cada vez mais, os governos precisam trabalhar com outros governos, setor privado, sociedade civil e cidadãos para alcançar muitos dos resultados que são importantes para as pessoas, que vão desde segurança alimentar até segurança nacional ou redução da pobreza. Nesses casos, é mais apropriado pensar em termos de governança do que de governo (DENHARDT e Denhardt, 2003).

Ao compartilhar responsabilidades, riscos e poder, os governos desempenham um papel cada vez mais difícil, mas fundamental. Eles devem usar sua autoridade de novas maneiras de modo a alavancar e desenvolver a força dos outros atores; assegurar partilha equitativa do risco entre as esferas pública, privada e civil; antecipar problemas e iniciar ações corretivas quando o interesse público o exigir.

- Cidadãos e outras partes interessadas (stakeholders) são agentes ativos e criadores de valor público. Cada vez mais questões de política pública exigem a participação ativa dos cidadãos e outros atores na criação de bens públicos comuns, especialmente quando tais questões vão além do poder legislativo e regulatório do Estado ou da capacidade de ação do governo. É também o caso quando as questões exigem mudança de comportamento individual e social (BIngham, Nabatchi e O'Leary, 2005).
Exemplos destes desdobramentos são abundantes. Governos podem fazer leis para a saúde pública, prevenção da criminalidade e proteção ambiental; podem cobrar impostos e realizar gastos para construir hospitais e custear serviços públicos de saúde; podem empregar forças policiais e fiscais. Mas as escolhas das pessoas e a forma como agem em casa, no trabalho, nas suas famílias e comunidades são os principais contribuintes para a saúde coletiva, segurança pública ou de um meio ambiente saudável.

Reconhecendo que precisam aproveitar a energia coletiva e as ideias dos cidadãos, muitos governos têm trabalhado no sentido de complementar as formas tradicionais de governar com novas formas que habilitam e empoderam os cidadãos. Ao avançar no sentido de produzir resultados junto com os cidadãos, governos atingem um conjunto mais completo de relacionamentos com eles.

Ao fazê-lo, também expandem o repertório de papéis que podem desempenhar para alcançar diferentes resultados públicos (Lenihan, Milloy, Fox e Barber, 2007). Governos podem atuar como:

- parceiro que usa os recursos e o poder do Estado para incentivar as contribuições dos cidadãos e outros atores;

- colaborador responsável e confiável em um sistema de governança compartilhada, que divide responsabilidades e recursos com cidadãos e outros atores na definição das questões, implementação de soluções e contabilização de resultados;

- facilitador, que estimula a criação e expansão de redes de governança colaborativa de auto-organização de atores e comunidades auto-organizadas que servem como plataformas para a cooperação, a inteligência coletiva e inovação social;

- liderança e agente pró-ativo que cria e se desenvolve junto com os outros em 
um sistema de governança adaptativa, que transforma o contexto e as ações de todos os atores para melhorar a probabilidade de resultados de políticas favoráveis.

Os governos têm ampla gama de opções, que vão desde atuar individualmente até o exercício da autoridade do Estado, com o qual alavanca o poder coletivo dos cidadãos e de outros atores da sociedade (ver Figura 2). As opções disponíveis no ambiente da "governança" requerem um sentimento compartilhado de responsabilidade, no qual os atores dentro e fora do governo estejam empoderados a contribuir com seu melhor para resolver problemas comuns de política pública; e onde os atores se comprometem mutuamente com os resultados e com alguma forma de responsabilização coletiva e individual (KeTTL, 2002), implicando também o compartilhamento apropriado e justo dos riscos e recompensas.
Essas opções não se baseiam em uma receita universal de "governança compartilhada" ou "coprodução" com a expectativa de que todo cidadão ou ator pode ou quer ser envolvido em todas as questões. Elas não apontam no sentido de intermináveis discussões e consultas. Também não significa que todas as decisões devam ser colaborativas. Em muitos casos, são necessárias decisões e ações de cima para baixo para a boa governança.

Não importa qual seja a opção de governança escolhida, em todos os casos, o governo continua a ser o gestor do interesse coletivo, com a responsabilidade de mediar entre as esferas pública, privada e da sociedade civil e com o poder de intervir quando o interesse público assim o exigir. Acontecimentos do passado recente, como a crise financeira mundial, nos lembram que o papel de gestão do governo tem recebido atenção insuficiente. $\mathrm{Na}$ verdade,

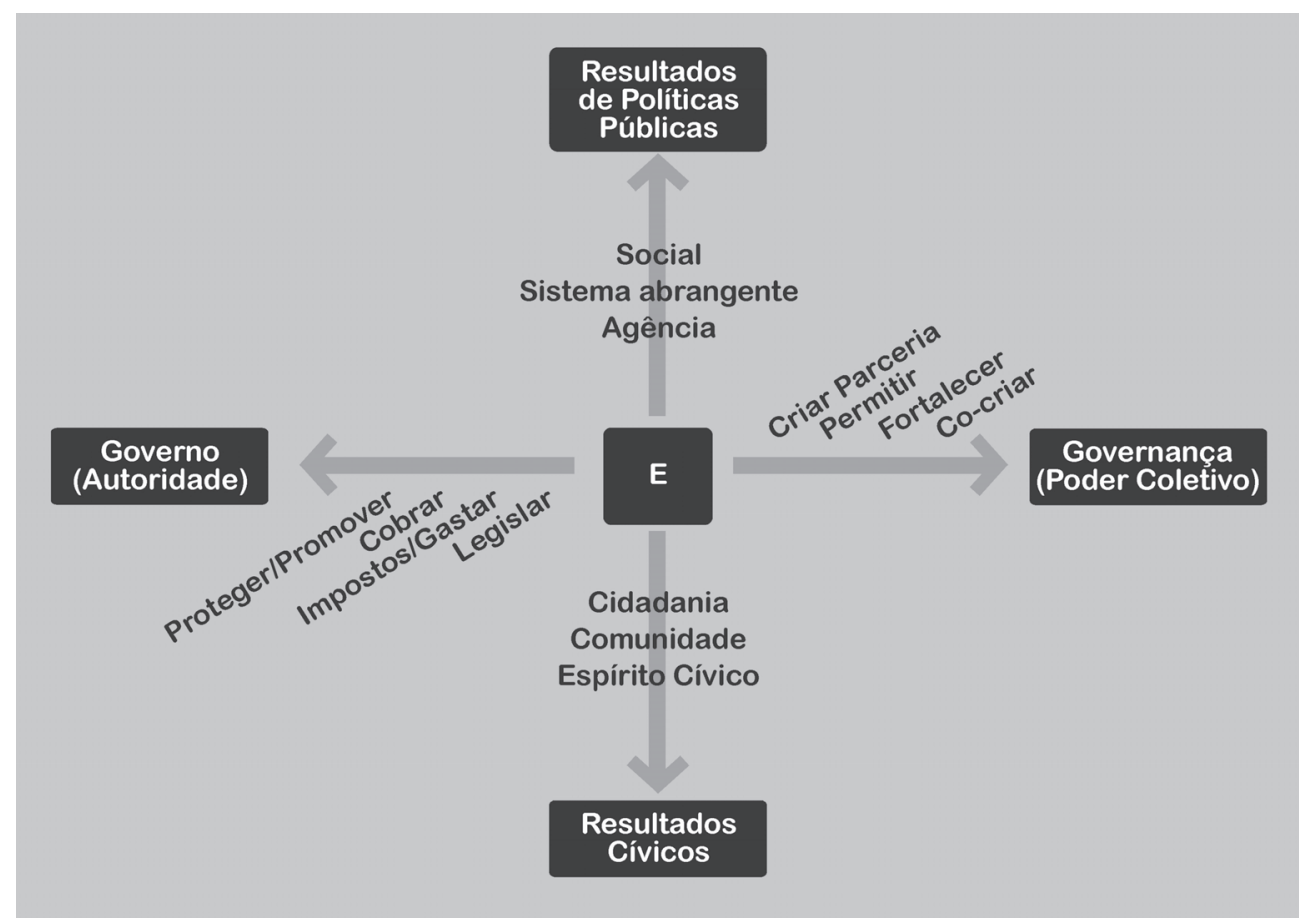

Figura 2: Autoridade, poder coletivo, papéis e resultados 
quanto mais dispersa a tomada de decisão e quanto mais distribuído o exercício do poder, mais importante se torna o papel de gestão do governo. Este papel envolve monitorar, antecipar e corrigir o curso.

Ao usar sua autoridade para empoderar outros atores para decidir e agir, o governo não está tomando uma atitude laissez-faire, nem reduzindo a sua posição em relação a outros atores no Estado. Em vez disso, está desempenhando uma combinação mais complexa de papéis que é afirmativa do Estado em nome do coletivo.

Visto por este prisma, o papel do governo está tomando forma em um espaço cada vez mais amplo de possibilidades que não é definido por um conjunto rígido e convencional de papéis e relacionamentos. Em vez disso, os administradores públicos, cidadãos e outros atores fazem parte de um sistema dinâmico, aberto e interativo de governança, onde a autoridade do Estado é utilizada de diferentes formas para alcançar diferentes resultados públicos - incluindo o engajamento e empoderamento de cidadãos, comunidades e outros atores a fim de obter resultados sociais e cívicos (ver Figura 3).

\section{O futuro da governança e da administração pública: um sistema dinâmico de capacitação}

Uma definição expandida de resultados públicos, combinada com uma visão mais ampla do papel do governo, cidadãos e outros agentes da sociedade fornece o espaço no qual novas direções para as reformas do serviço público podem tomar forma e no qual se podem explorar novas

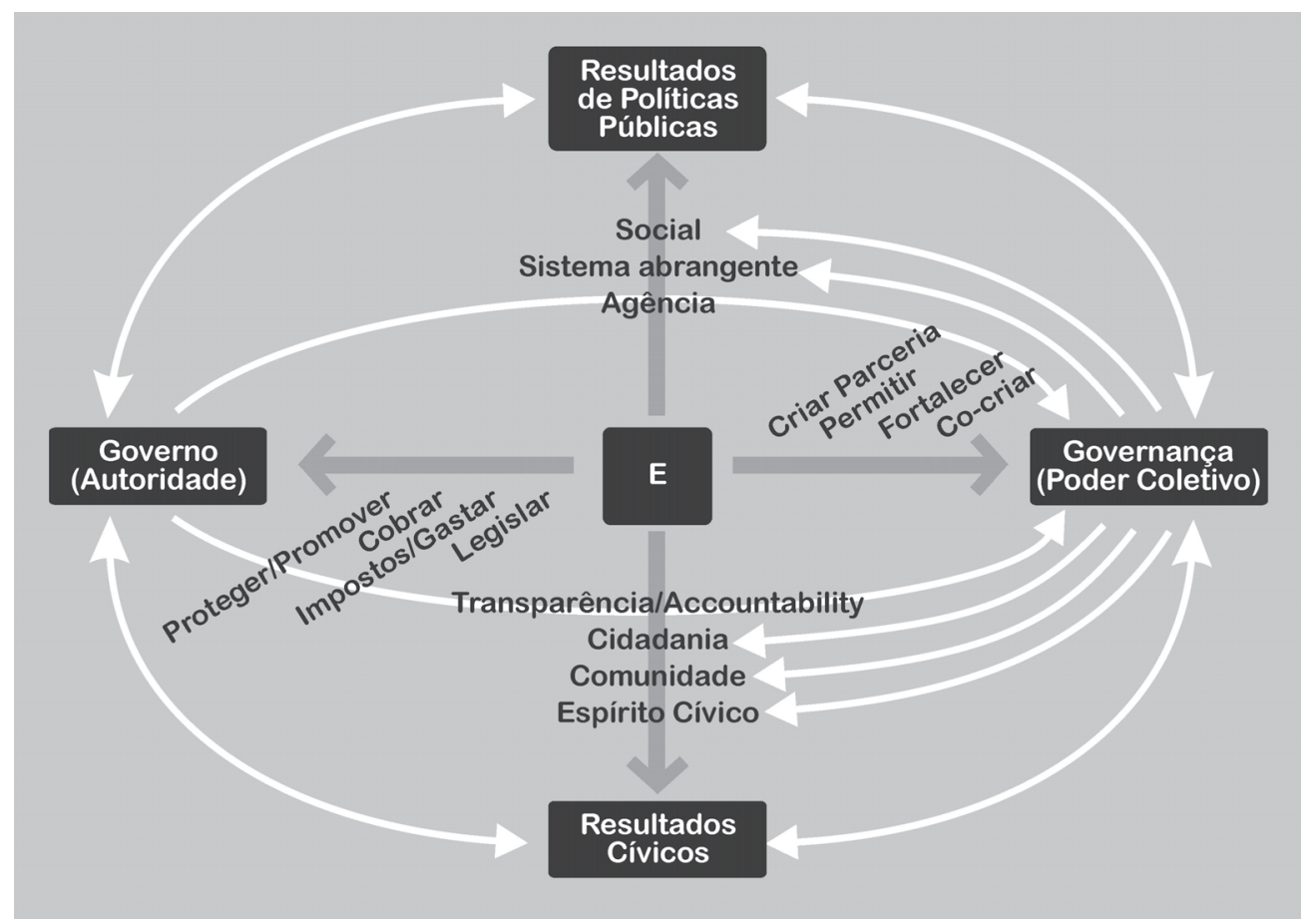

Figura 3: Sistema de governança dinâmico 
formas de desenvolver a capacidade coletiva no Estado para atingir resultados públicos (ver Figura 4).

\section{Desenvolvendo capacidades para servir - uma base sólida}

A administração pública envolve história, tradições e convenções. A construção da capacidade coletiva para alcançar resultados públicos começa por avaliar a evolução do passado e preservar as capacidades existentes, sendo crucial o foco na conformidade, que é a marca do bom governo, e inclui:

- o respeito pelo Estado de Direito e instituições públicas;

- devido processo legal, incluindo a equidade, transparência e responsabilização para o exercício dos poderes e uso de recursos públicos; e

- valores do setor público, incluindo a expectativa de que funcionários públicos, ao servir o bem comum, agirão com integridade, probidade e imparcialidade.

Juntos, esses fatores contribuem de maneira essencial para a capacidade institucional do aparelho estatal e fornecem uma base sólida para as organizações públicas. Eles representam o ponto de partida de qualquer jornada para a construção de um Estado. A capacidade institucional significa que o Estado tem capacidade de criar e fazer cumprir a legislação, cobrar impostos e gastar sem "vazamentos" ou corrupção, separar os poderes Legislativo, Executivo e Judiciário, e ter em conta o exercício do poder. Esta capacidade leva anos para ser implementada, e mantê-la é um processo infindável, de fundamental importância. As gerações futuras irão utilizá-la e dependerão dela, e serão encarregadas de renová-la.

Como não há bom governo sem boa performance das instituições do setor

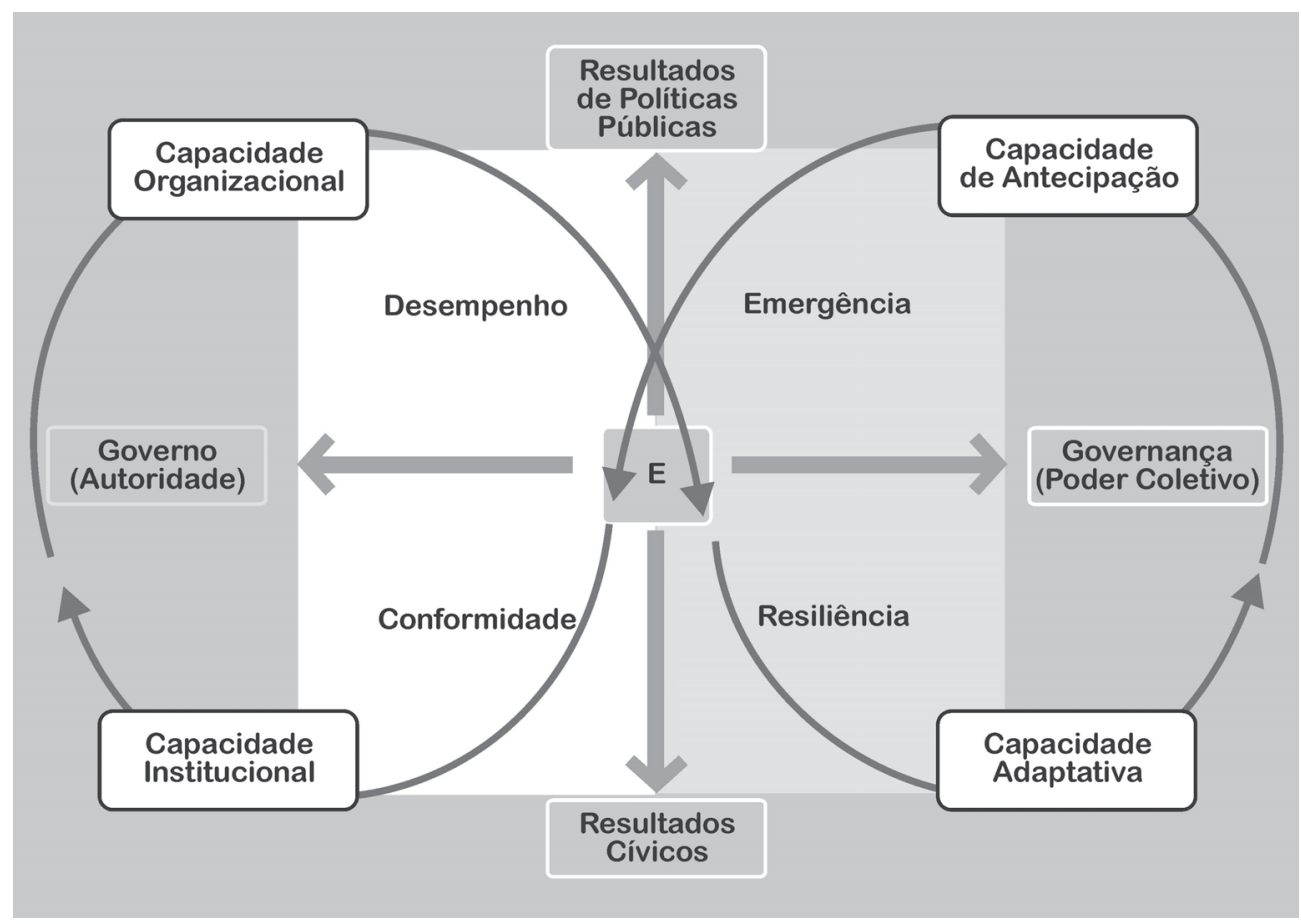

Figura 4: Sistema Dinâmico de Formação de Capacidades 
público, também é importante manter o foco que os governos têm colocado no desempenho ao longo das últimas duas décadas. As administrações públicas devem preservar e valorizar:

- a motivação interna de tornar o governo mais produtivo, eficiente e eficaz;

- a atenção na melhoria da prestação de serviços nos diferentes silos organizacionais e a necessidade de melhorias contínuas em resposta às expectativas dos cidadãos e à evolução das circunstâncias;

- o foco na boa governança, que incorpora outros setores e atores; e

- o poder das modernas tecnologias de comunicação e informação que estão transformando o papel do governo, a relação entre governo e cidadãos, bem como o papel do servidor público.

Esses fatores contribuem para o reforço das capacidades organizacionais, que formam a base para a obtenção de resultados públicos. Isso possibilita que bens públicos de alta qualidade possam ser entregues à sociedade ao menor custo possível; que a retroalimentação por usuários, a melhoria contínua e a inovação ocupem papel central na prestação de serviços públicos; que as tecnologias modernas de informação e comunicação sejam utilizadas para reduzir o número de intermediários e empoderar os usuários no processo de prestação de serviços. Possibilita também que as organizações das esferas públicas, privadas e da sociedade civil trabalhem juntas para alcançar resultados públicos comuns, embora, a capacidade de trabalhar além das fronteiras organizacionais deva primeiro ser aprendida dentro do governo, para assim facilitar que o governo alcance e trabalhe com outros setores da sociedade.

As tradições, modelos e capacidades relacionadas à conformidade e ao desempenho envolvem a construção de instituições públicas fortes e organizações públicas eficientes, que são de fundamental importância para qualquer governo. Elas se encaixam melhor em contextos estáveis, tarefas previsíveis e em uma abordagem centrada no governo para obtenção de resultados públicos; nessas circunstâncias, residem os pontos fortes e o valor agregado dessas instituições e organizações.

A questão é se um foco na conformidade e no desempenho será suficiente para os governos enfrentarem os desafios do século XXI.

A resposta a esta pergunta é, ao mesmo tempo, um exercício filosófico e pragmático para o governo. Diferentes países têm diferentes circunstâncias, necessidades e valores, e farão escolhas diferentes. É importante explorar as implicações dessas escolhas, uma vez que os governos são chamados a "servir além do previsível" (Bourgon, no prelo).

\section{Em busca de propósitos públicos em contexto de incerteza e complexidade}

O papel do governo hoje se estende além de atividades previsíveis e circunstâncias. Implica lidar com questões complexas - algumas das quais têm as características de "problemas perversos" (Ho, 2008) - no contexto imprevisivel da economia global e das sociedades em rede, no qual vários atores atuam simultaneamente.

A pressão sobre os governos é crescente para melhorar a sua capacidade de prever, antecipar-se e, se possível, prevenir-se contra crises que vão desde pandemias a colapsos econômicos globais, do aquecimento global à escassez de alimentos.

Desde a década de 1980, o mundo tornou-se muito mais interligado, em rede e "sem fronteiras" (Friedman, 2005). 
Problemas locais podem rapidamente tornar-se problemas globais, e problemas globais podem ter impactos locais significativos e imprevisíveis. Um número crescente de pessoas, grupos e organizações tomam decisões importantes em vários locais diferentes. Há uma crescente fragmentação. Suas decisões são influenciadas pelas decisões dos outros e por suas expectativas quanto ao que os outros possam fazer. Há crescente interdependência (KOPPERJAN e KLIjN, 2004). Com a fragmentação e a interdependência vem a incerteza.

Cada decisão e cada ação têm efeito limitado, mas o poder de decisões múltiplas que se deslocam em um sentido comum pode mudar o curso dos acontecimentos ao redor do mundo à velocidade da luz. ${ }^{8}$ Ideias sobre a "emergência" têm sido usadas para descrever este processo. Elas observam como novos padrões emergem de um vasto conjunto de interações e aparentemente do nada (Holland, 1998; Goldstein, 1999). Elas revelam os importantes papéis da autoorganização, adaptação e evolução em sistemas complexos (MitLeton-Kelly, 2008) e destacam as limitações dos "grandes projetos" para lidar com problemas em sistemas complexos, não importa o quanto esses planos sejam bem informados e concebidos (Bovaird, 2008; Westley, Zimmerman \& PATton, 2006).

As dificuldades que surgem para os governos enfrentarem a complexidade não se devem em particular à falta de conhecimento ou à deficiência dos funcionários públicos em comparação com seus antecessores. Elas surgem porque as abordagens convencionais em relação à governança e à administração pública não foram criadas ou concebidas para lidar com a complexidade e incerteza.

Certamente, problemas de interesse público em sua maioria são difíceis. Muitas vezes, a principal dificuldade reside na falta de conhecimento, capacidades, recursos ou tempo para resolvê-los. Eles podem ser superadas gradualmente, passo-a-passo, a partir do estabelecimento de prioridades que ajudem a resolver algumas dessas deficiências. Os exemplos nesse caso podem incluir reformas fiscais ou tributárias.

Alguns problemas são complicados. $\mathrm{O}$ conhecimento necessário para resolvê-los existe ou com certeza pode ser desenvolvido, mas o tamanho, escopo e escala são assustadores e o processo para produzir um resultado satisfatório é complexo e arriscado. Problemas complicados podem envolver uma rede elaborada de ações na qual cada ação, juntamente com sua continuidade e inter-relações, é fundamental para o sucesso e qualquer passo em falso pode levar ao fracasso. Exemplos aqui podem incluir a construção e execução de instalações nucleares ou missões espaciais (Westley et al., 2006).

A prática convencional que divide os empreendimentos em tarefas mais simples que podem ser executadas por intermédio de políticas e programas específicos foi desenvolvida para resolver problemas difíceis e complicados (WAGENAAR, 2007). Em face da complexidade, uma abordagem convencional pode deixar o governo em posição reativa, incapaz de detectar padrões emergentes em um ambiente em constante transformação e, portanto, incapaz de intervir de maneira antecipada.

Problemas complexos são de uma ordem diferente. Eles podem conter:

- Complexidade dinâmica, quando as causas e os efeitos são interdependentes, mas podem estar muito distantes no espaço e no tempo;

- Complexidade social, quando os fatos e a natureza do problema são contestados e as posições são solidamente estabelecidas; e 
- Complexidade generativa, quando questões únicas e imprevistas surgem com elevado potencial de recombinação de maneiras diferentes, em momentos diferentes, em lugares diferentes e em diferentes intensidades e escalas (Kahane, 2004).

Problemas dinamicamente complexos não podem ser resolvidos simplesmente por serem divididos em pedaços menores e a geração de mais conhecimento sobre cada parte. Eles só podem ser abordados ao se olhar para todo o sistema e, portanto, requerem uma abordagem sistêmica (Senge, 1990) que engloba os cidadãos e outros atores envolvidos e afetados (WagenaAr, 2007). O desmatamento na Floresta Amazônica é um exemplo de problema dinamicamente complexo que exige uma solução sistêmica. Mas o conhecimento sistêmico sozinho pode não ser suficiente para resolver problemas sociais complexos, na medida em que as definições, fatos e soluções são, muitas vezes, altamente contestados (Haveri, 2006; Kahane, 2004). Mas é cada vez mais claro que as definições e soluções que mais importam são aquelas criadas conjuntamente pelas partes interessadas. Mesmo que tal conhecimento seja imperfeito, o processo de criação conjunta detém maior valor, pois abre a possibilidade de ação coletiva articulada (SENGE, 2004). Os processos de reconciliação pós-segregação na África do Sul ou de reconstrução pós-conflito em algumas sociedades são exemplos de problemas de alta complexidade social (KAHANE, 2004; WESTLEY et al., 2006).

Problemas generativos complexos não podem ser resolvidos simplesmente com a replicação de ações anteriores (KAHANE, 2004). Mesmo que a situação tenha algumas semelhanças com acontecimentos passados, requer soluções emergentes que resultam da interação contínua e prevista dos atores e contextos, incluindo funcionários públicos e cidadãos. O desafio para os administradores públicos nesse caso é a leitura do ambiente complexo, conectar problemas, pessoas e soluções nos contextos corretos (Levinthal e WARGLIEN, 1999), e liberar o poder de auto-organização e coevolução (Duit e Galaz, 2008). O impacto potencial da mudança climática sobre pequenos Estados insulares, como a Indonésia, é um exemplo desse problema.

Problemas perversos contêm algumas ou todas as características de problemas complexos, juntamente com um nível particularmente elevado de incerteza e imprevisibilidade. Incertezas decorrem da fragmentação do processo decisório e da interdependência de ações relacionadas ao problema. A imprevisibilidade decorre de relações instáveis entre os muitos atores e variáveis. O aquecimento global é um exemplo de problema perverso que exige uma combinação adaptativa de soluções sistêmicas, sociais e emergentes.

Uma série de teorias, conceitos e ferramentas têm sido desenvolvidas desde a década de 1990 para ajudar os profissionais a enfrentar a complexidade em um ambiente de incerteza (por exemplo, GUNDERSON e Holling, 2002; Mitleton-Kelly, 2008; Teisman \& KuIjn, 2008), mas não existe fórmula mágica (Bovaird, 2008). Confrontar tal ambiente requer novas capacidades. Isso começa com o governo reconhecendo a complexidade e a incerteza como parte de sua realidade e aceitando que tem um papel a desempenhar que vai além do previsível (HAYNEs, 2003). É necessário compreender as implicações e consequências deste novo papel para as organizações e servidores públicos. Deve-se buscar um conjunto coerente de ações para apoiar esse novo papel do governo. 


\section{Construção de capacidade de antecipação, inovação e adaptação}

Enfrentar com sucesso a complexidade e a perversidade, como parte da realidade da administração pública, requer esforços conjuntos para construir a capacidade do governo de antecipar, detectar e intervir proativamente sempre que necessário. Isso também irá implicar a construção da capacidade coletiva de antecipação, inovação e adaptação (ver Figura 4).

Detectar precocemente através de processos de varredura ou de outros meios, e obter um melhor entendimento sobre as perspectivas dos vários atores e as relações entre eles podem reduzir incerteza e imprevisibilidade. A ação proativa pode aumentar a probabilidade de resultados mais desejáveis. Os países com as melhores capacidades de detectar tendências e antecipar mudanças significativas terão uma importante vantagem comparativa.

A maioria dos governos tem desenvolvido funções relativamente fortes de política interna, que são necessárias para prestação de boa assessoria em políticas, levando em conta capacidades existentes e lições aprendidas no passado. Em geral, as unidades de políticas são baseadas em departamentos e missões específicas; tendem a valorizar a racionalidade causal e o raciocínio linear; e dependem fortemente de dados e evidências - e por boas razões. Esse tipo de abordagem tem contribuído para grandes realizações em várias áreas das políticas públicas.

Mas, no caso de questões complexas e possibilidades emergentes, o conhecimento mais importante não reside nos dados, mas se baseia em interpretação e inspiração, na identificação de padrões prováveis onde antes nada havia sido identificado, e no sentido extraído de informações difusas e conhecimento imperfeito. Esse trabalho requer uma diversidade de perspectivas provenientes das interações entre os múltiplos atores, uma diversidade de habilidades de bases de conhecimento de diferentes disciplinas, e uma diversidade de abordagens nas quais o pensamento linear, sistemas de pensamento não linear e uma compreensão emergente coexistam.

Muitos governos têm longa tradição de coleta de informações, de varredura ambiental, planejamento de cenários, modelagem e avaliação de riscos. O desafio é estender essa capacidade para questões complexas e ambientes imprevisíveis, dando prioridade ao desenvolvimento da capacidade de antecipação de governo. Alguns países já estão adotando medidas ambiciosas nesse sentido (Habegger, 2009). Por exemplo, Cingapura está usando uma abordagem transversal no governo que conjuga planejamento de cenários com avaliação de risco e um sistema de escaneamento de horizonte. ${ }^{9}$ Vários ministérios no Reino Unido se uniram para financiar e usar um "programa de previsão" para conduzir "pesquisa de futuros" em setores específicos como saúde, energia e uso da terra. ${ }^{10} \mathrm{O}$ parlamento finlandês estabeleceu entre os seus membros um "Comitê para o Futuro", com o mandato de submeter propostas sobre temas relacionados ao futuro e conduzir estudos sobre questões futuras. ${ }^{11}$

Inferindo a partir de exemplos atuais, a capacidade de antecipação nas políticas baseia-se em uma abordagem ampla de governo, com ferramentas que capturam informações de ampla variedade de fontes e permitem acesso a uma variedade de atores dentro e fora do governo. Apoiase na liderança do cerne do governo, mas exige disponibilização de dados, capacidades analíticas e interpretativas nas agências executoras, departamentos e organizações 
fora do governo, como universidades e grupos de reflexão. Essa capacidade poderia ser reforçada por mais diálogo dentro do governo e entre o governo e uma gama mais ampla, mais diversificada de atores externos.

Em muitos casos, o melhor conhecimento, a inteligência e as descobertas mais poderosas sobre os fenômenos emergentes não se encontram no governo. Eles estão nas mentes das pessoas comuns, na casa ao lado ou a milhares de quilômetros de distância; são moldados e circulam em redes sociais auto-organizadas e nos diferentes relacionamentos que os cidadãos têm em suas comunidades locais ou comunidades de interesse dispersas globalmente (SChuler, 2008).

Para tratar de problemas complexos e da incerteza, os governos precisam melhorar sua capacidade de explorar a inteligência coletiva da sociedade para extrair conhecimento e significado sobre os padrões e as tendências emergentes no sistema social. Os cidadãos e outros atores têm informações preciosas e diversas perspectivas que podem fornecer antevisão, moldar decisões e encontrar soluções inovadoras (AtLee, 2008; Malone, 2008).

Os governos podem também tomar medidas para incentivar a inovação social (Mulgan, 2007). As redes sociais e as capacidades dos cidadãos são poderosos ativos na geração de novas soluções e na busca de novos cursos de ação visando objetivos sociais (Westley, Zimmerman e Patton, 2006). O governo pode alavancar o poder das redes para conectar atores, problemas e soluções como um meio de se alcançar resultados públicos (KLIJN, 2008).

Essas ações podem contribuir para fazer o governo avançar de uma postura reativa para uma situação mais adaptativa. Em geral, elas resultam na construção de capacidade de antecipação e inovação dentro e fora do governo.

Não obstante os esforços realizados por governos e cidadãos para construir sua capacidade de antecipação e inovação para a resolução de problemas públicos, eventos não previstos e choques inesperados ocorrerão. O governo será sempre o garantidor em última instância, quando o interesse coletivo estiver em jogo. A história recente mostra, por exemplo, com a eclosão da Gripe Aviária em 2003 e o quase colapso do sistema financeiro mundial em 2008, que as abordagens passivas para lidar com "surpresas" e questões emergentes de política pública podem trazer danos significativos e um custo elevado para sociedade. Embora os governos não possam planejar para o que eles não conhecem, eles podem trabalhar proativamente para limitar o impacto de choques e aumentar a probabilidade de resultados mais favoráveis.

O papel do governo no século XXI se estende para a construção da resiliência de suas sociedades para absorver os choques, aceitar mudanças e prosperar. Desde a década de 1990, ideias sobre como o governo pode estimular a resiliência têm sido desenvolvidas, particularmente no que diz respeito à gestão de crises, segurança e preparação para emergências (por exemplo, Allenby e Fink, 2005; Hanson e Roberts, 2005; Masten e Obradovic, 2008; Menon, 2005; Norris et al., 2008). Os campos da ecologia e dos estudos ambientais, que têm um registro mais completo da pesquisa sobre resiliência, são boas fontes de inspiração (por exemplo, Anderies, Walker e Kinzig, 2006; Gunderson e Holding, 2002; Holling, 1973, 2001). Orientação promissora para os administradores públicos está emergindo. 
Alguns choques podem ser previstos, ainda que apenas como probabilidades. Construir resiliência implica planejar, prevenir e antecipar esses choques, e identificar e reduzir as principais vulnerabilidades a eles associadas (ADGER, 2006; Berkes, 2007; McManus et al., 2007).

Alguns choques não podem ser previstos, evitados ou mitigados. Além disso, mudanças são inevitáveis e podem ser saudáveis (BERKES e FOLKE, 2002), embora os benefícios e os custos possam ser distribuídos de forma desigual (NorRIs et al., 2008; SCHEFFER et al., 2002). A tentativa de impedir todos os choques pode acabar por criar comunidades, instituições e sociedades "frágeis", na medida em que prejudica a capacidade coletiva de aprender e adaptar-se (COMFORT, 1994; GUNDERSON et al., 1995). Atrasar a mudança pode aumentar o risco de crises de grande escala mais tarde (Holling e Meffe, 1996).

A meta para o governo não é tentar prever ou controlar todos os potenciais choques. Isso seria impossível e contraproducente. Pelo contrário, o objetivo principal é promover a resiliência da sociedade, o que significa construir capacidade coletiva para aprender e se adaptar e garantir uma distribuição mais equitativa dos riscos, de forma a atenuar o impacto negativo nos mais vulneráveis da sociedade.

A resiliência não pode ser alcançada por indivíduos, organizações ou governos trabalhando sozinhos (McManus et al., 2007). Sociedades resilientes têm pelo menos duas características importantes: 1) cidadãos ativos, compreendendo uma massa crítica de pessoas com motivação, habilidades e confiança para adotar medidas que satisfaçam às necessidades de suas comunidades, e 2) redes sólidas de grupos comunitários com a capacidade de reunir ampla gama de pessoas para identificar as necessidades da comunidade e mobilizar recursos em prol de soluções comuns (Dale e Onyx, 2005).

Essas capacidades são desenvolvidas por intermédio da experiência e da prática. A abordagem participativa para decisões de políticas públicas e implementação de políticas é essencial na construção de capacidades de adaptação coletiva. A participação pública, o envolvimento do cidadão e as abordagens de governança compartilhada fornecem poderosos reforços para a resiliência, particularmente se tais abordagens encorajam ações e tomadas de decisão pela comunidade (LEBEL et al., 2006). Lidar com problemas em nível local também evita a escalada de problemas no sistema social, assim impedindo que se tornem crises de grande magnitude (BERKES e FOLKE, 2002).

A resiliência e a capacidade de adaptação não podem ser compradas ou obtidas nos momentos em que são mais necessárias. Elas se desenvolvem a partir da experiência e prática adquiridas (Berkes e FolKe, 2002); advêm de laços e relações construídas ao longo do tempo entre pessoas, organizações, comunidades e governos que aprenderam que podem trabalhar juntos e contar uns com os outros quando precisam. A resiliência se baseia em um estoque de confiança, entendimento mútuo, conhecimento e aprendizado que permitem às pessoas agirem, aprenderem, adaptarem-se e evoluirem coletivamente (LONGSTAFF e Yang, 2008; Murphy, 2007; Newman e DaLe, 2005).

Os governos podem fazer muito para construir a capacidade adaptativa dos cidadãos, comunidades e deles próprios, incluindo:

- intervir na menor escala possível antes que problemas se tornem de grande escala; 
- experimentar e investir em projetospiloto em âmbito local e em seguida expandir quando apropriado;

- simular eventos que ampliem a aprendizagem coletiva; e

- acelerar a transferência de conhecimentos e aprendizado entre os atores.

Os gestores públicos podem melhorar a capacidade de antecipação, inovação e adaptação de suas organizações mantendo um nível de redundância estratégica e alimentando as fontes de renovação. Eles podem proteger os recursos para exploração e descoberta. Podem conservar e construir novas capacidades, tais como uma função política adepta à antecipação estratégica, monitoramento e resposta dinâmica. Eles podem criar "espaços seguros" ou incubadoras que forneçam ambientes propícios à experimentação e à inovação. Podem também aceitar a diversidade em termos de pessoas e funções para fornecer ampla gama de opções diante da adversidade.

Implementar muitas das medidas para melhorar as capacidades de antecipação e inovação - e, com elas, melhorar a capacidade do governo para enfrentar a complexidade e se recuperar de choques e adversidades - exigirá alguns investimentos direcionados para o longo prazo e tolerância quanto a uma pequena quantidade de capacidade "excedente" que será necessária em organizações públicas. Em última análise, isso exigirá o reconhecimento de que menos governo e governo mais eficaz, não significam, necessariamente, melhor governo.

\section{Considerações finais}

Foram necessários séculos e muito sacrifício para construir nossos EstadosNação modernos e um grande empenho para construir as sociedades civis que os compõem. A arte e a ciência da governança e da administração pública têm desempenhado papel importante na construção das capacidades institucionais e organizacionais para alcançar os resultados públicos e servir ao interesse coletivo. Profissionais e estudiosos da área têm muito a se orgulhar.

As transformações ocorridas no mundo desde a década de 1980, juntamente com as crises globais recentes, indicam a necessidade de se procurar um novo equilíbrio entre o mercado e a democracia; entre os interesses públicos e privados; entre a liberdade na esfera privada e responsabilidade comum na esfera coletiva.

Um novo equilíbrio exige novas capacidades, novas ideias e novos conhecimentos que complementem os que vieram anteriormente.

Como um esforço profissional e acadêmico, a arte e a ciência da governança e da administração pública têm uma coerência interna singular, nascida do direito constitucional e da ciência política. Com o tempo, ela internalizou ideias e práticas da economia e da gestão de negócios, integrou conhecimentos das ciências organizacionais e se enriqueceu com ideias das ciências sociais.

Aqueles que praticam e estudam governança e administração pública devem, mais uma vez, explorar novas fronteiras, já que começam a integrar ideias de muitas áreas do conhecimento - desde a complexidade às teorias de sistemas adaptativos, da inteligência coletiva às teorias de rede, e da biologia evolutiva e ecologia à epidemiologia e segurança nacional. Tudo isso irá fornecer concepções importantes para o futuro da governança e da administração pública, além de motivar o processo de desenvolvimento de capacidades de 
antecipação, inovação e adaptação. Também irá fornecer ideias sobre a necessidade de reformulação da construção de capacidades institucionais e organizacionais.

Acima de tudo, pode ser hora de reencontrar alguns conceitos muito antigos de bem público, interesses coletivos, democracia, civismo e cidadania e explorar o seu significado no panorama de constante mudança da realidade de hoje.

Utilizar uma estrutura de integração pode ser útil para guiar a exploração e as inter-relações entre antigas e novas ideias. Uma possibilidade é aproveitar a estrutura conceitual que foi desenvolvida como parte de programa internacional de pesquisa realizado atualmente pela autora sobre uma "nova síntese na administração pública” (ver Figura 5), que subsidiou a este documento. ${ }^{12}$

Em última análise, toda a exploração quanto ao futuro da administração pública pode ser feita de maneira mais eficaz por profissionais, acadêmicos e especialistas trabalhando em conjunto, porque a investigação e a prática são partes inseparáveis de um empreendimento comum.

(Artigo recebido em dezembro de 2009. Versão final em março de 2010)

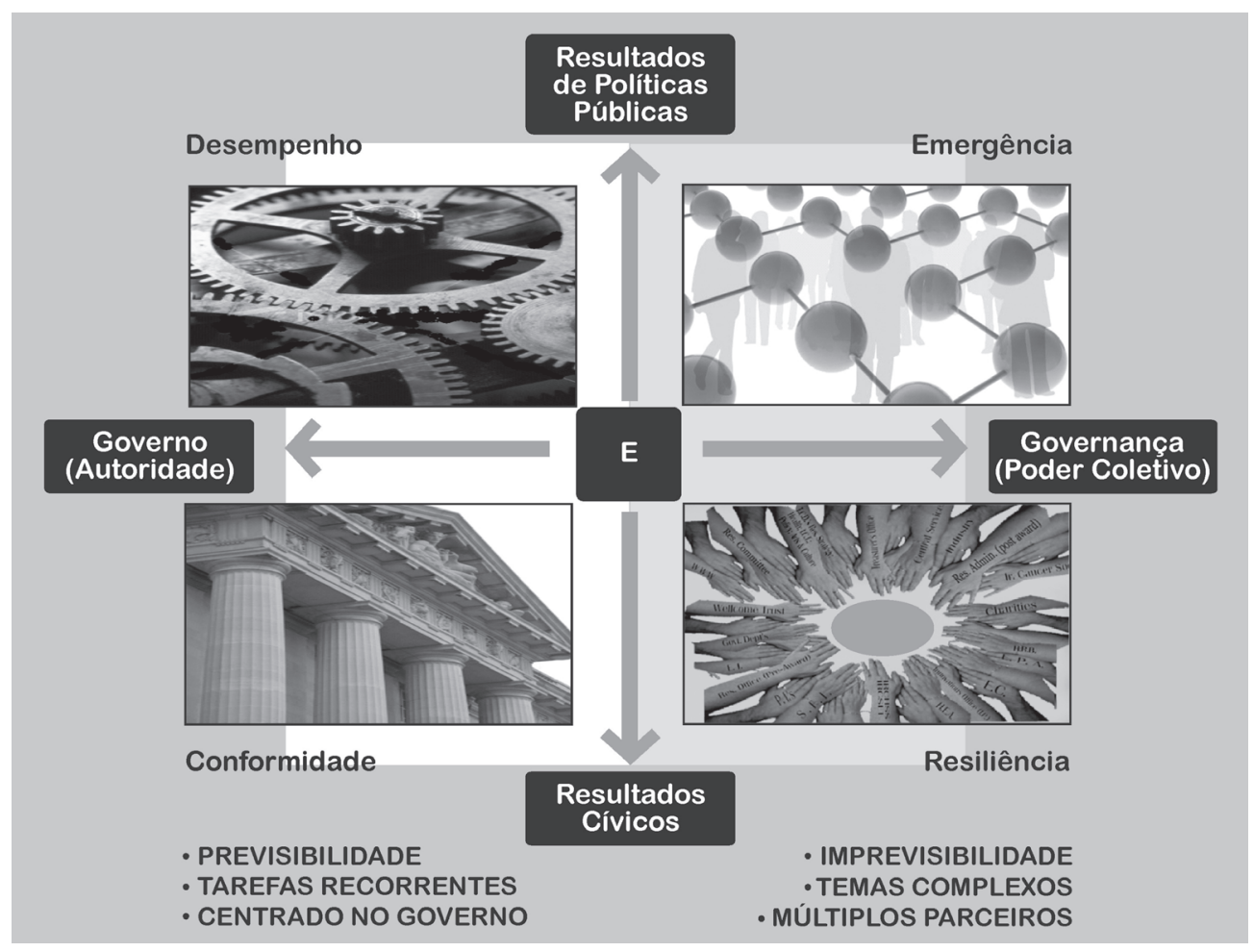

Figura 5: Unificando uma estrutura de administração pública 


\section{Notas}

1 Veja, por exemplo, o relatório do Conselho de Progresso da Província de Colúmbia Britânica, no Canadá na página http:/ / www.bcprogressboard.com.

2 Por exemplo, Chile, Uruguai e Guatemala aprovaram legislação de acesso à informação em 2008 (Michener, 2009). Essa evolução foi reforçada por uma resolução unânime do Comitê Jurídico Interamericano da Organização dos Estados Americanos que reconhece o acesso à informação como um direito humano fundamental (AcostA et al, 2008).

3 Por exemplo, o México ampliou sua base de compras do setor público na internet em dois novos programas: DeclaraNet e TransmitaNet. DeclaraNet é um sistema eletrônico para preenchimento e apresentação de declarações de imposto de renda e TransmitaNet é um catálogo de formulários do Estado. O Brasil tem tido sucesso com o voto eletrônico desde 2000. Argentina e México têm usado máquinas brasileiras de voto eletrônico em projetos-piloto e o Paraguai utilizou o modelo brasileiro de votação em sua eleição de 2003 (PADGET, 2005).

4 O Sistema Único de Saúde (SUS) do Brasil, por exemplo, incorpora a participação dos cidadãos na deliberação sobre a política de saúde como um mecanismo para garantir a responsabilização, a adequação do processo de decisão, e a eficácia da prestação dos serviços. O SUS delegou papéis a parceiros do setor privado, depois que foram feitos acordos entre os municípios e o setor privado, de modo que compras substanciais foram feitas de clínicas e hospitais privados, de forma a atender as diversas necessidades descobertas no processo de consulta (CORNIVALl e SHANKL.AND, 2008).

5 Por exemplo, abordagens participativas para o orçamento, a gestão e despesas públicas em Porto Alegre, Brasil, têm conseguido resultados observáveis. Agora, mais de $80 \%$ das cidades brasileiras já utilizaram o modelo de Porto Alegre (Wold Bank: Equipe de Participação e Engajamento Cívico, 2003).

${ }^{6}$ Em termos de papéis e expectativas dentro do governo, aqueles que têm a autoridade para governar - se a autoridade decorre de processos eleitorais ou outros meios constitucionais - são, em última instância, responsáveis pela definição da intenção das políticas. Essa intenção representa o ponto de partida para o papel dos administradores públicos que têm à sua disposição várias formas e meios para atingir os resultados desejados, incluindo a utilização de processos de participação pública.

7 Por exemplo, o envolvimento do cidadão em grande escala foi instituído para formular o plano para a reconstrução de Nova Orleans depois do furacão Katrina. Milhares de cidadãos se envolveram com os planejadores e funcionários para tratar uma questão política complexa. Esse compromisso foi visto como um fator-chave para revitalizar a esperança e o senso de plenitude na comunidade após a devastação (LuKENSMEYER, 2007). No Brasil, as melhorias nos indicadores de saúde entre 1992 e 2004 mostram o êxito da abordagem consultiva do SUS. Durante aquele período, os números de mortalidade abaixo de cinco anos de idade caíram de 65 para 27 por mil, e a proporção de famílias pobres com acesso aos serviços aumentou em quase metade (CORNWALL e SHANKI_AND, 2008).

8 Esta condição é perfeitamente capturada no famoso "efeito borboleta", segundo o qual o bater de asas de uma borboleta em Pequim pode mudar os padrões climáticos no Golfo do México (Morgan, 2006, p. 255).

9 Ver http://www.rahs.org.sg.

${ }_{10}$ Ver http://www.foresight.gov.uk/index.asp.

11 Ver http://web.eduskunta.fi/Resource.phx/parliament/committees/future.htx.

12 Para informações sobre o projeto "nova síntese", ver http://www.ns6newsynthesis.com 


\section{Referências}

Acosta, Silvina and Emilene Martinez-Morales (2008). Documenting Access to Information in Latin America - Legal Milestones and Success Stories, (28September2008), Freedominfo.org: the online network of freedom of information adbvocates (Washington), Retrieved September 1, 2009 from http://www.freedominfo.org/features/20080928a.htm.

Adger, W.N. (2006). Vulnerability. Global Environmental Change, 16: 268-281.

Allenby, B. and Fink, J. (2005). Toward Inherently Secure and Resilient Societies. Science, 309: 1034-1036.

Anderies, J.M., Walker, B.H. and Kinzig, A.P. (2006) Fifteen Weddings and a Funeral: Case Studies and Resilience-based Management. Ecology and Society, 11(1), 21-32.

Atlee, T. (2008). Co-Intelligence, Collective Intelligence, and Conscious Evolution. In M. Tovey (ed.), Collective Intelligence: Creating a Prosperous World at Peace [pp. 5-14]. Oakton, VA: Earth Intelligence Network.

Baltodano, A.P. (1997) The study of public administration in times of global interpenetration: a historical rational for a theoretical model, Journal of Public Administration Research and Theory, 7.4 (1997): 615-638

BerKes, F. (2007). Understanding Uncertainty and Reducing Vulnerability: Lessons from Resilience Thinking. Natural Hazards, 41: 283-295.

Berkes, F. \& Folke, C. (2002). Back to the Future: Ecosystem Dynamics and Local Knowledge. In L.H. Gunderson and C.S. Holling (eds.), Panarchy: Understanding Transformations in Human and Natural Systems [pp. 121-146]. Washington, DC: Island Press. Bingham, L. B., Nabatchi, T. and O'Leary. R. (2005) The New Governance: Practices and Processes for Stakeholder and Citizen Participation in the Work of Government. Public Administration Review, 65(5), 547-558.

Bourgon, J. (2007) Responsive, responsible and respected government: Towards a New Public Administration Theory. International Institute of Administrative Sciences, 73 (1), 7-26. Bourgon, J. (2008a) Performance Management: It's the results that count. Asian Pacific Journal of Public Administration, 30(1), 41-58.

Bourgon, J. (2008b) The future of public service: A search for a new balance. Australian Journal of Public Administration, 67(4):390-404.

Bourgon, J. (2009) Why Should Governments Engage Citizens in Service Delivery and Policy Making? In Organisation for Economic Cooperation and Development (ed.), Focus on Citizens: Public Engagement for Better Policy and Services. Paris: OECD, 171-177. Retrieved January 2, 2009 from http://www.olis.oecd.org/olis/2008doc.nsf/LinkTo/ NT00005FB6?OpenDocument.

Bourgon, J. (In press) New Directions in Public Administration: Serving Beyond the Predictable. Public Policy and Administration, 24(3).

Bovaird, T. (2008) Emergent Strategic Management and Planning Mechanisms in Complex Adaptive Systems. Public Management Review, 10(3), 319-340. 
COMfort, L. (1994). Risk and Resilience: Inter-organizational Learning Following the Northridge Earthquake of 17 January 1994. Risk and Resilience, 2(3): 157-170.

Cornwall, Andrea and Alex Shankland.(2008) Engaging Citizens: Lessons from building Brazil's national health system. Social Science and Medicine, 66: 2173-2184.

Dale, A., and J. Onyx. (2005) A Dynamic Balance: Social Capital and Sustainable Community Development. Vancouver, BC: UBC Press.

Denhardt, J.V. \& Denhardt, R.B. (2003) The New Public Service, Serving, not Steering. Armonk, NY: E. Sharpe.

Duit, A. and Galaz, V. (2008). Governance and Complexity - Emerging Issues for Governance Theory. Governance: An International Journal of Policy, Administration, and Institutions, 3 (21): 311-335.

Friedman, T.L. (2005) The World is Flat: A Brief History of the 21 $1^{\text {st }}$ Century. New York, NY: Farrar, Straus and Giroux.

Fung, A. and Wright, E.O. (2003). Deepening Democracy: Institutional Innovations in Empowered Participatory Governance. London, UK: Verso Press.

Goldstein, J. (1999) Emergence as a Construct: History and Issues. Emergence: Complexity and Organization, 1, 49-72.

Gunderson, L.H., Holding, C.S. and Light, S.S. (1995). Barriers and Bridges to the Renewal of Ecosystems and Institutions. New York, NY: Columbia University Press.

Gunderson, L.H. and Holling, C. (Eds.) (2002) Panarchy: Understanding Transformations in Human and Natural Systems. Washington, DC: Island Press.

Habegger, B. (2009). Horizon Scanning in Government. Zurich: Centre for Security Studies. Retrieved June 17, 2009 from http://se2.isn.ch/serviceengine/ FileContent? serviceID $=11 \&$ fileid $=3$ D 89E3D1-55A8-8622-F380-69C677A36478 \&lng=en.

Hanson, B. and Roberts, L. (2005). Resiliency in the Face of Disaster. Science, 309: 1029.

Haveri, A. (2006). Complexity in Local Government Change: Limits to Rational Reforming. Public Management Review, 1(8): 31-46,

Haynes, P. (2003) Managing Complexity in the Public Services. Maidenhead, UK: Open University Press.

Ho, P. (2008) Governance at the Leading Edge: Black Swans, Wild Cards and Wicked Problems. Ethos 4, 74-79.

Holland, J.H. (1998) Emergence: From Chaos to Order. Reading, MA: Helix Books.

Holding, C.S. (1973) Resilience and Stability of Ecological Systems. Annual Review of Ecology and Systematics, 4, 1-23.

HolLing, C.S. (2001) Understanding the complexity of economic, ecological, and social systems. Ecosystems, 4(5):390-405.

Holding, C.S. and Meffe, G.K. (1996). Command and Control and the Pathology of Natural Resource Management. Conservation Biology, 10: 328-337. 
Huddleston, M. (2000) Onto the darkling Plain: globalization and the American public Service in the twenty first century. Journal of Public Administration Research and Theory, 10(4): 665-684.

InNEs, J. E., \& BOOHER, D. E. (2004). Reframing public participation: Strategies for the 21st century. Planning Theory \& Practice, 5(4), 419-436.

Irvin, R. and Stansbury, J. (2004) Citizen Participation in Decision Making: Is it Worth Effort? Public Administration Review, 64(1), 55-65

Kahane, A. (2004). Solving Tough Problems: An Open Way of Talking, Listening and Creating New Realities. San Francisco, CA: Berrett-Koehler Publishers.

Khator R. and Garcia-Zamor, J-C., Introduction. In J-C. Garcia-Zamor (Ed.) Public administration in the global village. Westport, CT.: Praeger, 1994

KetTl, D. (2002) The Transformation of Governance: Public Administration for Twenty-First Century America. Baltimore, MD: The Johns Hopkins University Press.

KLIJN, E-H. (2008) Complexity Theory and Public Administration: What's New? Public Management Review, 10(3), 299-317.

KLIjN, E-H. (2005) Networks and Inter-Organizational Management: Challenging, Steering, Evaluation, and the Role of Public Actors in Public Management, in E. Ferlie, Lynn, L. \& PolditT, C. (eds) The Oxford Handbook on Public Management. New York, NY: Oxford University Press.

Koppenjan, J. and KLijn, E-H. (2004) Managing Uncertainties in Networks: A Network Approach to Problem-Solving and Decision-Making. London, UK: Routledge.

Lebel, L., Anderies, J.M., Campbell, B., Folke, C., Hatfield-Dodds, S., Hughes, T.P., and Wilson, J. (2006). Governance and the Capacity to Manage Resilience in Regional Social-Ecological Systems. Ecology and Society, 11(1), 19-37.

Lenihan, D., Milloy, J., Fox, G., \& Barber, T. (2007) Progressive Governance for Canadians: What You Need to Know. Ottawa, ON: Public Policy Forum.

Levinthal, D. A. and Warglien, M. (1999). Landscape Design: Designing for Local Action in Complex Worlds. Organizational Science, 10 (3): 342-357.

Longstaff, P.H. \& Yang, S. (2008). Communication Management and Trust: Their Role in Building Resilience to "Surprises" Such as Natural Disasters, Pandemic Flu, and Terrorism. Ecology and Society, 13(1). Retrieved April 21, 2009 from http:// www.ecologyandsociety.org/vol13/iss1art3/main.html.

LUKENSMEYER, C. J. (2007). Large-scale citizen engagement and the rebuilding of New Orleans: A case study. National Civic Review, 96(3), 3-15.

Malone, T.W. (2008). What Is Collective Intelligence and What Will We Do About It? In M. Tovey (ed.), Collective Intelligence: Creating a Prosperous World at Peace [pp. 1-4]. Oakton, VA: Earth Intelligence Network.

Mahbubani (2009). The Dangers of Democratic Delusions. Ethics and International Affairs, (1) $23,19-25$.

Masten, A.S. and Obradovic, J. (2008). Disaster Preparation and Recovery: Lessons from Research on Resilience in Human Development. Ecology and Society, 13(1): 9-36. 
McManus S., Seville, E., Brundon, D., and Vargo, J. (2007) Resilience Management: A Framework for assessing and improving the resilience of organizations. Resilient organizations research programme. University of Canterbury: Christchurch, New Zealand. Retrieved January 2, 2009 from http://www.resorgs.org.nz/pubs.shtml.

Menon, K.U. (2005) National Resilience: From Bouncing Back to Prevention. Ethos, 11(1), 14-17.

Michener, Greg (2009) Freedom of Information Legislation and the Media in Latin America.(19May2009),Freedominfo.org: the online network of freedom of information adbvocates (Washington), Retrieved September 1, 2009 from http://www.freedominfo.org/features / 20090519.htm.

Mitleton-Kelly, E. (2008) Ten Principles of Complexity and Enabling Infrastructures. In E. Mitleton-Kelly (ed.) Complex Systems and Evolutionary Perspectives on Organisations: The Application of Complexity Theory to Organisations [p. 23-51]. Bingley, UK: Emerald Group Publishing Limited.

Morgan, G. (2006) Images of Organization. Thousand Oaks, CA: Sage.

Mulgan, G. (2007) Social Innovation: What is it, Why it Matters and How it can be Accelerated. Skoll Center for Social Entrepreneurship Working Paper, SAID Business School, University of Oxford, 1-51. Retrieved January 2, 2009 from http:// www.youngfoundation.org.uk/files/images/03_07_What_it_is__SAID_.pdf

Murphy, B.L. (2007). Locating Social Capital in Resilient Community-level Emergency Management. Natural Hazards, 41: 297-315.

Newman, L.L., and DaLe, A. (2005) Network structure, diversity, and proactive resilience building: a response to Tompkins and Adger. Ecology and Society, 10(1). Retrieved January 24, 2009 from http://www.ecologyandsociety.org/vol10/iss1/resp2.

Norris, F., Stevens, S.P., Pfefferbaum, B., Wyche, K.F. and Pfefferbaum, R.L. (2008). Community Resilience as a Metaphor, Theory, Set of Capacities, and Strategy for Disaster Readiness. American Journal of Community Psychology, 41: 127-150.

Nye, J.S., Zelikow, P.D. and King, D.C. (Eds.). (1997). Why People Don't Trust Government. Boston, MA: Harvard University Press.

Organization for Economic Cooperation and Development. (2008) From Open to Inclusive: Building Citizen-centered Policy and Services. Retrieved January 2, 2009 from http:/ / www.olis.oecd.org/olis/2008doc.nsf/ENGDATCORPLOOK/NT00000E9A/ \$FILE/JT03243619.PDF

PAdGeT, Julian. (2005) E-Government and E-Democracy in Latin America. IEEE Intelligent Systems 20(1): 94-96.

Pharr, S.J. and Putnam, R.D. (Eds.). (2000). Disaffected Democracies: What's Troubling the Trilateral Countries? Princeton, NJ: Princeton University Press.

Salamon, L. (2002) The Tools of Government: A Guide to the New Governance. Oxford, UK: Oxford University Press.

Senge, P. (1990). The Fifth Discipline: The Art and Practice of the Learning Organization. New York, NY: Doubleday. 
Senge, P. (2004). Preface. In A. Kahane, Solving Tough Problems: An Open Way of Talking, Listening and Creating New Realities. San Francisco, CA: Berrett-Koehler Publishers.

Scheffer, M., Westley, F., Brock, W.A., Holmgren, M. (2002). Dynamic Interaction of Societies and Ecosystems-Linking Theories from Ecology, Economy and Sociology. In L.H. Gunderson and C.S. Holling (eds.), Panarchy: Understanding Transformations in Human and Natural Systems [pp. 195-239]. Washington, DC: Island Press.

SChuler, D. (2008). Civic intelligence and the public sphere, in M. Tovey, Collective intelligence: creating a prosperous world at peace. Oakton, VA: Earth Intelligence Network.

Teisman, G.R. \& Klijn, E.-H. (2008). Complexity Theory and Public Management, Public Management Review 10(3): 287-297.

United Nations. (2007) Public Administration and Development. Report of the SecretaryGeneral. Sixty-second session, General Assembly. Retrieved January 2, 2009 from http:/ /unpan1.un.org/intradoc/groups/public/documents/un/unpan027432.pdf

Van Dooren, W., Thijs, N. and Bouckaert, G. (2004) Quality Management and the Management of Quality in European Public Administration. In E. Loffler and M. Vintar (Eds.), Improving the Quality of East and West European public Services, 91-106.

Wagenaar, H. (2007) Governance, Complexity, and Democratic Participation: How Citizens and Public Officials Harness the Complexities of Neighborhood Decline. The American Review of Public Administration, 37(1), 17-50.

Westley, F., Zimmerman, B \& Patton, M. (2006) Getting to Maybe: How the World is Changed. Toronto, ON: Random House.

World Bank, Participation and Civic Engagement Team (2003). Case Study 2 - Porto Alegre, Brazil: Participatory Approaches in Budgeting and Public Expenditure Management. Social Development Notes, 71 (March 2003), Retrieved September 3, 2009 from http:/ / info.worldbank.org/etools/docs/library/238102/1.1.2\%20sdn71.pdf. 


\section{Resumo - Resumen - Abstract}

\section{Finalidade pública, autoridade governamental e poder coletivo} Jocelyne Bourgon

Desde a década de 1980, as reformas têm dominado as agendas governamentais em todo o mundo; os governos embarcaram em uma notável jornada de inovação. O ritmo dessas reformas provavelmente não irá diminuir.

O número crescente de desafios na política pública demanda a participação ativa de inúmeros atores dentro e fora do governo e requer que o governo trabalhe para além dos limites convencionais. Esses desafios forçam o governo a utilizar sua autoridade e recursos para habilitar e empoderar outros. O aumento da complexidade e da incerteza nas questões de política e nos contextos de governança levam os governos a aprimorar sua capacidade de antecipar, intervir, inovar, aprender e adaptar-se. Futuras reformas irão requerer uma visão mais ampla dos papéis do governo e dos cidadãos. Embora o governo continue a ser o garantidor dos interesses coletivos com o poder de intervir, ele precisa descobrir como pode trabalhar com os cidadãos e outros atores como o objetivo de produzir resultados de elevado valor público. Enquanto governos avançam para produzir resultados com os cidadãos, eles atingem um conjunto mais completo de relações e ampliam o repertório de papéis que cada um pode desempenhar para obterem resultados. Estas reformas permitirão uma definição mais ampla de resultados públicos que enfatizam a importância das políticas públicas e dos resultados cívicos. Estes últimos conferem credibilidade, enquanto os primeiros aumentam a legitimidade. Ambos aumentam a confiança dos cidadãos no governo. Os administradores públicos têm, até agora, trabalhado a partir de uma definição incompleta de resultados que não confere peso suficiente aos resultados cívicos.

Finalmente, futuras reformas também exigirão uma compreensão mais dinâmica da governança e da administração pública que apoie o desenvolvimento de capacidades. É necessário o desenvolvimento de competências em novas áreas para se buscar o bem público em um ambiente global cada vez mais imprevisível, mas esse trabalho deve começar pela valorização e preservação das capacidades existentes. $O$ foco na conformidade é primordial, a marca de um bom governo. Isso inclui: o respeito ao Estado de Direito e às instituições públicas, o devido processo legal, a responsabilização (accountability) e os valores do setor público. Esses fatores contribuem para proporcionar uma sólida base institucional para as organizações públicas. Os administradores públicos devem também preservar o seu foco no desempenho. Isso inclui: tornar o governo mais produtivo e eficiente; melhorar a prestação de serviços articulando "silos" organizacionais; responder às expectativas dos cidadãos; melhorar os processos de governança; e otimizar o poder das tecnologias de informação e comunicação modernas.

Apesar dos esforços coordenados para construir no âmbito do governo a capacidade de antecipar, detectar e intervir, eventos imprevisíveis e choques vão ocorrer. Por essa razão, o governo também deve focar na resiliência, construindo capacidade de inovar, aprender e se adaptar, e assegurando uma distribuição mais equitativa dos riscos. Implementar medidas para melhorar as capacidades de previsão, inovação e adaptação exigirá investimentos direcionados para o longo prazo e tolerância de algum "excesso" de capacidade. Finalmente, isso exigirá o reconhecimento de que "menos governo" ou "governo mais eficiente" não significa necessariamente "melhor governo".

Palavras-Chave: Gestão pública, autoridade governamental, poder público, resultados públicos, novos desafios, desenvolvimento de capacidades 


\section{Finalidad pública, autoridad gubernamental y poder colectivo}

\section{Jocelyne Bourgon}

Desde la década de 1980, las reformas han dominado las agendas gubernamentales en todo el mundo; los gobiernos embarcaron en una notable jornada de innovación. El ritmo de estas reformas probablemente no se va a disminuir. El número creciente de retos en la política pública demanda la participación activa de varios actores dentro y fuera del gobierno y requiere que el gobierno trabaje más allá de los límites convencionales. Estos retos fuerzan al gobierno a la utilización de su autoridad y recursos para habilitar y otorgar poderes (empower) a los otros. El aumento de la complejidad y de la incertidumbre en las cuestiones políticas y en los contextos de gobernanza hace que los gobiernos desarrollen su capacidad de anticipación, intervención, innovación, aprendizaje y adaptación. Reformas futuras requerirán visión más amplia de los papeles del gobierno y de los ciudadanos. Aunque el gobierno siga siendo aquello que garantiza los intereses colectivos con el poder de intervención, él necesita descubrir cómo se puede trabajar con los ciudadanos y otros actores, con el objetivo de producir resultados de elevado valor público. Mientras los gobiernos avancen para la producción de resultados con los ciudadanos, ellos alcanzan un conjunto más complejo de relaciones y amplían el repertorio de papeles que cada uno puede desarrollar para la obtención de resultados. Estas reformas permitirán una definición más amplia de resultados públicos que enfatizan la importancia de las políticas públicas y de los resultados cívicos. Estos dan credibilidad, mientras aquellas aumentan la legitimidad. Ambos aumentan la confianza de los ciudadanos en el gobierno. Los administradores públicos han, hasta ahora, trabajado a partir de una definición incompleta de los resultados, que no confiere suficiente importancia a los resultados cívicos.

Finalmente, futuras reformas tambíen exigirán comprensión más dinámica de la gobernanza y de la administración pública, que apoye el desarrollo de capacidades. Es necesario el desarrollo de competencias en nuevas áreas para que se busque el bien público en ambiente global cada vez más imprevisible, pero este trabajo debe empezar por la valoración y conservación de las capacidades existentes. El foco en la conformidad es primordial, es la marca de un buen gobierno; lo que incluye: el respeto al Estado de Derecho y a las instituciones públicas, el debido proceso legal, la responsabilización (accountability), y los valores del sector público. Estos factores contribuyen para propiciar una sólida base institucional para las organizaciones públicas. Los administradores públicos deben incluso mantener su foco en el desempeño; lo que incluye: hacer que el gobierno sea más productivo y eficiente; mejorar la prestación de los servicios articulando "silos" organizacionales; responder a las expectativas de los ciudadanos; mejorar los procesos de gobernanza; y optimizar el poder de las tecnologías de información y comunicación modernas.

Pese a los esfuerzos coordinados para construir en el ámbito del gobierno la capacidad de anticipación, detección e intervención, eventos imprevisibles y choques van a ocurrir. Por esa razón, el gobierno también debe enfocar la resiliencia, contruyendo capacidad de innovación, aprendizaje y adaptación, y asegurando una distribución de los riesgos con más equidad. La implementación de medidas para mejorar las capacidades de previsión, innovación y adaptación exigirá inversiones a largo plazo y tolerancia hacia algún "exceso" de capacidad. Por fin, esto demandará el reconocimiento de que "menos gobierno" o "gobierno más eficiente" no significa necesariamente "mejor gobierno".

Palabras clave: Gestión pública, autoridad gubernamental, poder público, resultados públicos, nuevos retos, desarrollos de capacidades 


\section{Public purpose, government authority and collective power}

\section{Jocelyne Bourgon}

Since the 1980s, reforms have dominated government agendas around the world; governments embarked on a remarkable journey of innovation. The pace of reform is not likely to abate.

An increasing number of public policy issues call for the active contribution of many actors across and beyond government and require government to work outside of conventional boundaries. They compel government to use its authority and resources to enable and empower others. Increased complexity and uncertainty within policy issues and governance contexts are prompting governments to improve their ability to anticipate, intervene, innovate, learn, and adapt. Future reforms will necessitate an expanded view of the roles of government and citizens. While government remains the steward of collective interest with the power to intervene, government needs to explore how it can work with citizens and other actors to produce results of high public value As governments move towards producing results with citizens, they strike a more complete set of relationships and expand the repertoire of roles each can play to achieve results. These reforms will allow a broader definition of public results that emphasizes the importance of both public policy and civic results. The latter build credibility, while the former increase legitimacy. Both enhance citizens' trust in government. Public administrators have thus far been working from an incomplete definition of results that does not give sufficient weight to civic results.

Finally, future reforms will also require a more dynamic understanding of governance and public administration that supports the building of capacity. Capacity building in new areas is required to pursue the public good in an increasingly unpredictable global environment, but this work must begin by valuing and preserving existing capacities. Central among these is the focus on compliance, the hallmark of good government. It includes: a respect for the rule of law and public institutions; due process; accountability; and public sector values. These factors contribute to providing a solid institutional foundation for public organizations. Public administrators should also preserve their focus on performance. This includes: making government more productive and efficient; improving service delivery across organizational silos; being responsive to the expectations of citizens; improving governance processes; and harnessing the power of modern information and communication technologies.

Notwithstanding concerted efforts to build government capacity to anticipate, detect and intervene, unpredictable events and shocks will occur. Given this, government must also focus on resilience by building the capacity to innovate, learn and adapt, and by ensuring a more equitable distribution of risks. Implementing measures to improve anticipative, innovative and adaptive capacities will require targeted investments for the long term and tolerance of some "excess" capacity. Ultimately, this will require recognition that less government, and more efficient government, does not necessarily amount to better government.

Keywords: Public Administration, government authority, public power, public results, new challenges, capacity development

Jocelyne Bourgon

A Honorável Senhora Jocelyne Bourgon, PC, OC. Distinguished Fellow, do Centro de Inovação em Governança Internacional. Presidente Emérita, Escola Canadense de Serviço Público. Contato: jocelyne.bourgon@csps-efpc.gc.ca 


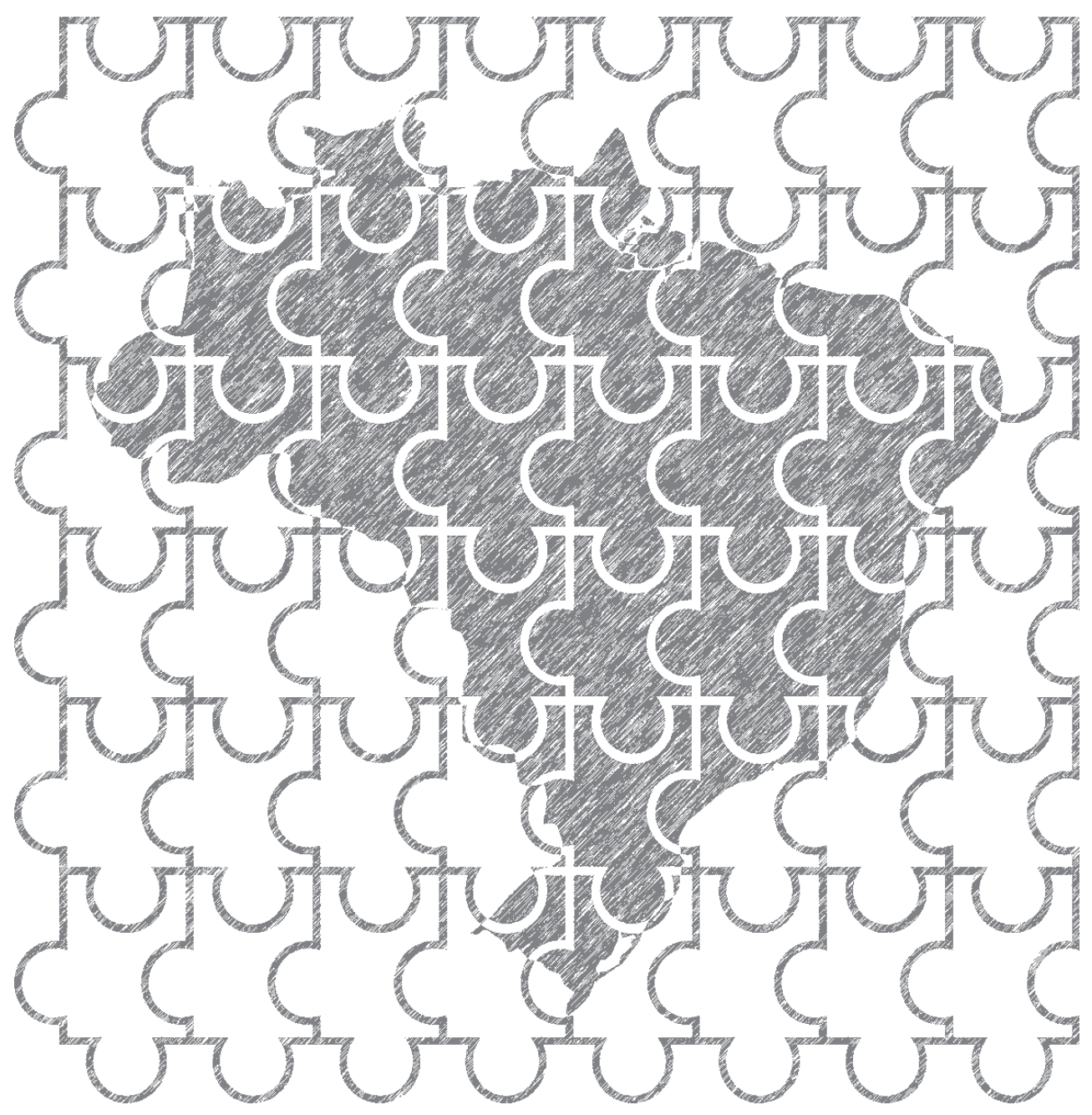

